\title{
Neighbourhood air quality and snoring in school-aged children
}

\author{
Leila Kheirandish-Gozal' ${ }^{1}$ Mirfarhad Ghalebandi², Mansour Salehi², \\ Mohammad Hosein Salarifar ${ }^{3}$ and David Gozal ${ }^{1}$
}

Affiliations: 'Section of Pediatric Sleep Medicine, Dept of Pediatrics, University of Chicago, Chicago, IL, USA. ${ }^{2}$ Tehran Psychiatric Institute, Mental Health Research Center, Iran University of Medical Sciences, Tehran, Iran, and ${ }^{3}$ Dept of Psychology, University of Birjand, Birjand, Iran.

Correspondence: L. Kheirandish-Gozal, Section of Pediatric Sleep Medicine, Dept of Pediatrics, Pritzker School of Medicine, The University of Chicago, 5841 S. Maryland Avenue/MC2117, Chicago, IL 60637-1470, USA. E-mail: Igozallapeds.bsd.uchicago.edu

ABSTRACT The prevalence of habitual snoring has been extensively explored in paediatric populations. Although exposure to cigarette smoke increases the risk of habitual snoring in a dose-dependent fashion, the potential contribution of air quality to habitual snoring remains unclear.

6000 questionnaires were distributed to 6- to 12-year-old children attending public schools in five distinct neighbourhoods within the city of Tehran, Iran, that were preselected based on air quality measures. Habitual snoring was defined as loud snoring $\geqslant 3$ nights per week. Information regarding clinical and family-related habitual snoring risk factors was also obtained. Descriptive statistics followed by adjusted risk assessments were conducted.

Among the $4322(72 \%)$ completed datasets, the prevalence of habitual snoring was $11.6 \%$. Partition of habitual snoring rates according to neighbourhood air quality characteristics revealed significantly higher habitual snoring frequencies among children residing in neighbourhoods with greatest pollution $(24.5 \%$ and $12.1 \%$ in South and Central neighbourhoods versus $7.0 \%$ and $7.7 \%$ in North and East neighbourhoods, respectively). The regional variance in habitual snoring was primarily accounted for by an integrated measure of air quality, even after controlling for other risk factors.

Environmental air quality emerges as a significant and potentially modifiable contributor to the risk for developing habitual snoring during childhood.

@ERSpublications

Environmental pollution is an important and modifiable contributor to habitual snoring in schoolaged children http://ow.ly/rHP9L

Received: July 032013 | Accepted after revision: Aug 122013 | First published online: Aug 292013

Support statement: D. Gozal is supported by National Institutes of Health grants HL-65270, HL-086662, and HL-107160.

Conflict of interest: None declared.

Copyright @ERS 2014 


\section{Introduction}

Snoring in school-aged children is a frequent occurrence that not only illustrates the presence of increased upper airway resistance during sleep, but is also one of the major symptoms of obstructive sleep apnoea (OSA). A large number of studies have thus far evaluated the prevalence of habitual snoring in paediatric populations all over the world. Based on variable definitions used for habitual snoring, the prevalence of habitual snoring ranged from $2.5 \%$ to $>20 \%$ of all children, with a median of $10-12 \%$ [1-9]. Separately, habitual snoring has been strongly and independently associated with behavioural hyperactivity, learning and behavioural problems, restless sleep and poor academic performance, even in the absence of OSA $[4,7,8,9-11]$. Furthermore, habitual snoring has also been linked to an increased risk of elevated systemic blood pressure and nocturnal enuresis $[12,13]$.

The major risk factors enumerated for the presence habitual snoring include a positive family history of snoring, prematurity, obesity, ethnic characteristics, early life history of respiratory syncytial virus bronchiolitis, lower socioeconomic status, allergies, asthma and passive exposure to cigarette smoke [1-11, 14-18]. More specifically, exposure to cigarette smoke increased the risk of habitual snoring in a dose-dependent fashion, such that the highest prevalence was found when both parents smoked [1, 18-21]. However, the impact of environmental pollution on habitual snoring has not been extensively assessed. ZHANG et al. [22] reported that nitrogen dioxide levels inside the home were higher in children who habitually snored, and similar findings have been recently reported regarding ambient particulate matter exposures in adults [23]. In addition, we recently reported that exposure to increased biomass indoor pollution is associated with an inordinately elevated prevalence of habitual snoring in children living in developing regions of Peru [24]. We should further emphasise that long-term exposure to air pollutants has been associated with increased risk of many respiratory illnesses in children, such as allergies, asthma and respiratory infections, with potentially long-term adverse implications [25].

Despite the fact that air quality in most cities within the developed world has been subjected to stringent monitoring and standards for motor vehicle and industrial emissions, air pollution is still a major issue in the vast majority of metropolitan areas. Substantial concerns about the long-term effects of sustained exposures to different air pollutants such as particulate matters (particles with a $50 \%$ cut-off aerodynamic diameter of $2.5 \mu \mathrm{m}$ and $10 \mu \mathrm{m}$ (PM10)), ozone, sulfur dioxide, nitrous oxides $\left(\mathrm{NO}_{\mathrm{x}}\right)$ and carbon monoxide have been raised in large-cohort studies [26, 27].

Based on the aforementioned considerations, this study was designed to examine the potential associations between habitual snoring and exposure to air pollutants in a large metropolitan environment with unique topographical characteristics, namely the city of Tehran, Iran. The major hypothesis of the present study was that the prevalence of habitual snoring in children living in neighbourhoods that exhibit higher air pollution levels would be higher than in those with less air pollution.

\section{Methods \\ Study design and population}

The study was approved by institutional ethics board of the Iran University of Medical Sciences and by the University of Louisville Human Research Committee (protocol \#474.99). A total of 6000 validated questionnaires $[9,28,29]$ were distributed over a period of 3 months during late 2007 and early 2008. 1800 of the children invited to participate were between the ages of 5 and 7 years and the remaining 4200 children were aged 8-12 years. All children attended public schools in five distinct districts within the city of Tehran during the data collection period.

The five districts were selected based on the officially published air quality measures by the governmental Air Pollution Control Company corresponding to the four cardinal directions (north, south, east and west) and the central district of the city. The city of Tehran is divided into 22 districts, with different elevations and socioeconomic statuses. In order to achieve the maximum distinction between neighbourhoods, two imaginary lines crossing each other with the right angle at the centre of the city were drawn and the four cardinal direction districts, as well as one central district, were selected (fig. 1 and tables 1 and 2). From each district, four public schools were randomly selected for distribution of the questionnaires.

\section{Exposure assessments \\ Air pollution}

In Tehran, the air monitoring stations are operated by the Air Pollution Control Company and routinely measure several major pollutants: PM10, sulfur dioxide, nitrogen dioxide, carbon monoxide and ozone. The quality of air in these five regions was determined by the pollutant standards index (PSI), which included values for these five air pollutants measured on a daily basis in stations located within the selected regions during the years 2006-2007 (fig. 1). The analytical monitors in each station are fully automated, and also 


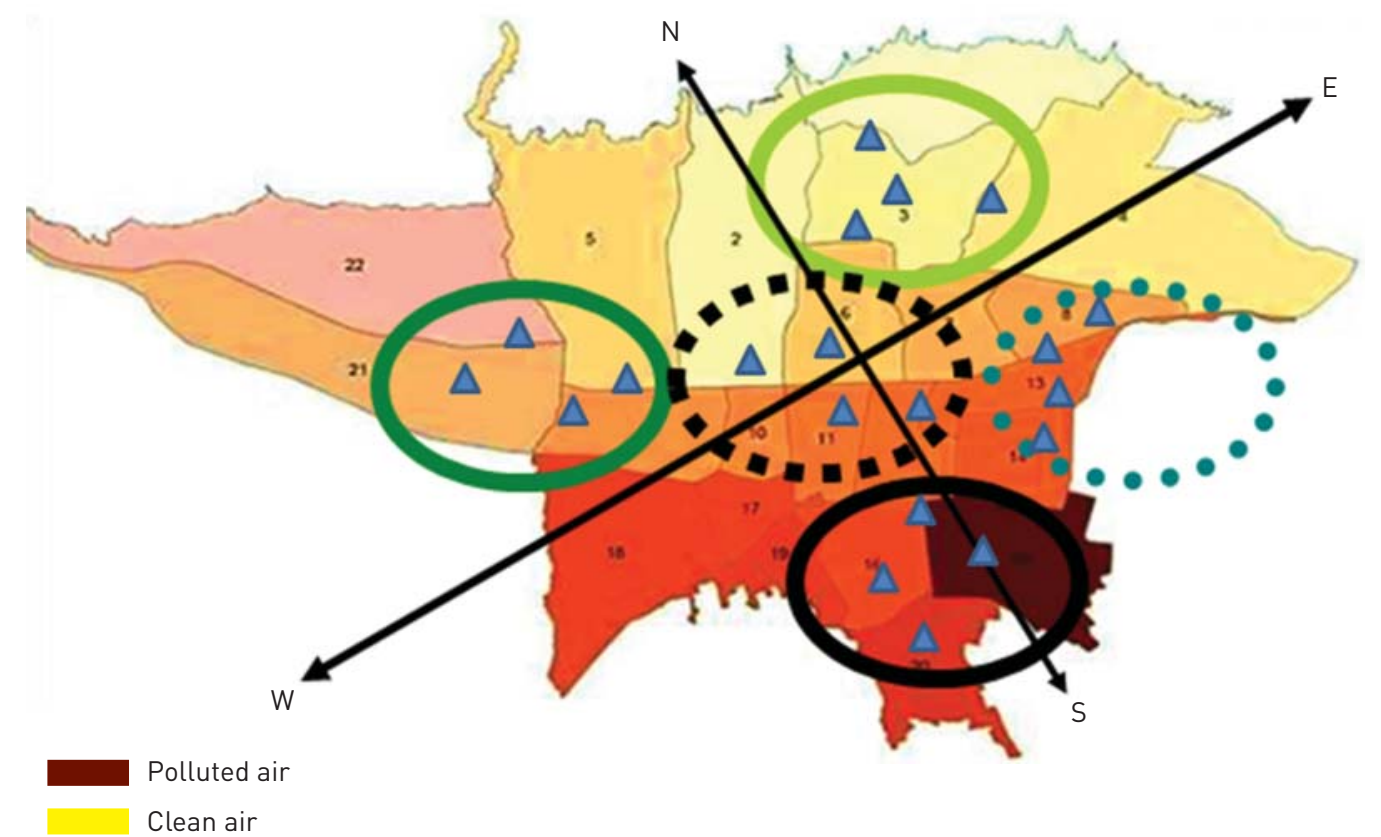

FIGURE 1 Representative map of the city of Tehran based on air pollution reports for the years 2006-2007. The five regions from which schools were selected for the present survey are indicated by ellipses. A green solid line indicates very low pollution levels and a black solid line indicates very high pollution levels. Dotted lines indicate intermediate-high (black) or low (green) pollution levels. Colours ranging from burgundy (polluted air) to yellow (clean air) represent a scale of intensity of pollution. Blue triangles indicate school locations.

include a daily automated calibration system. Once a year, the stations conduct quality control and quality assurance tests. PM10 was measured by Verewa Extractive Beta Gauge Particulate Monitor (Model F-701; Durag Inc., St Paul, MN, USA), sulfur dioxide by a Fluorescence $\mathrm{SO}_{2}$ Analyser (Model 43C; Thermo Environmental Instruments Inc., Franklin, MA, USA), nitrogen dioxide by Chemiluminescence NO- $\mathrm{NO}_{2}-$ $\mathrm{NO}_{x}$ analyser (Model 42C; Thermo Environmental Instruments Inc.), ozone by U.V. Photometric $\mathrm{O}_{3}$ Analyzer (Model 49C; Thermo Environmental Instruments Inc.) and carbon monoxide by a Gas Filter Correlation CO Analyzer (Model 48C; Thermo Environmental Instruments Inc.).

\section{Questionnaire}

The questionnaire used in this study was based on a previously validated questionnaire $[9,28,29]$. The questionnaire was translated into Farsi, and then independently retranslated back to English, to ascertain that no changes in the content and meaning of each question occurred. Parents of the children invited to participate received the questionnaire, which included questions regarding family history of snoring, parental smoking habits, child's past medical history and current use of medications, as well as information regarding allergies, asthma, previous adenotonsillectomy, recurrent ear infections, ear tube placement. Habitual snoring was defined as loud snoring $\geqslant 3$ nights per week.

\section{Data analysis}

Descriptive analyses were employed to summarise the attributes and characteristics of the subjects based on snoring. To examine associations between potential risk factors and habitual snoring clusters, multivariable logistic regression models were used. The main approach consisted of comparisons between habitual snoring and all others. In addition to age and sex, the following variables were considered for inclusion in the models. 1) Environmental exposures: including parental smoking (none, one parent or both parents), number of siblings and neighbourhood of residence; 2) socioeconomic factors: including paternal and maternal education (primary school, middle school, high school or university), presence of overcrowding $(>1$ person per room); and 3) clinical features and symptoms: including child history of atopic disease, upper and lower respiratory symptoms in the child, prevalence and frequency of wheeze, chronic cough, recurrent ear infections, adenotonsillectomy (yes/no) and placement of tympanostomy tubes (yes/no).

To explore potential causal pathways in our data, we developed three logistic regression models with incremental complexity. First, we generated a simple model that was adjusted only for age and sex. Then, a second model was adjusted for all familial risk factors, and the third model was adjusted for other clinical 
TABLE 1 Mean neighbourhood air pollution levels, 2006-2007 in Tehran, Iran

City region

Mean air pollution levels

\begin{tabular}{lccccc}
\cline { 2 - 5 } & $\begin{array}{c}\text { Carbon monoxide } \\
\mathbf{p p m}\end{array}$ & $\begin{array}{c}\text { Nitrogen dioxide } \\
\mathbf{p p b}\end{array}$ & $\begin{array}{c}\text { 0zone } \\
\mathbf{p p b}\end{array}$ & $\begin{array}{c}\mathbf{P M 1 0} \\
\boldsymbol{\mu g} \cdot \mathbf{m}^{-\mathbf{3}}\end{array}$ & $\begin{array}{c}\text { Sulfur dioxide } \\
\mathbf{p p b}\end{array}$ \\
\hline North & 5.7 & 29.3 & 78.7 & 42.9 & 21.3 \\
South & 3.6 & 94.8 & 112.4 & 106.8 & 46.6 \\
East & 1.3 & 39.7 & 88.8 & 66.8 & 13.7 \\
West & 1.6 & 45.6 & 76.7 & 63.0 & 10.3 \\
Central & 5.5 & 76.0 & 104.6 & 90.4 & 39.4 \\
\hline
\end{tabular}

PM10: particles with a $50 \%$ cut-off aerodynamic diameter of $10 \mu \mathrm{m}$.

features. Finally, a model was constructed by adjusting for environmental and clinical conditions simultaneously, i.e. a fully adjusted model. All variables associated with prevalence of habitual snoring $(\mathrm{p}<0.05)$ in one model were included in the next modelling steps, except when the information contained in two or more variables was so similar (co-linear) that only one could be taken into the next modelling step. For example, these circumstances became applicable in the case of paternal and maternal education, current parental smoking and home crowding. Findings are described as risk ratios with $95 \%$ confidence intervals. We calculated the population-attributable risk fraction, which corresponds to the proportion of habitual snoring that could be prevented assuming causality of the associations and elimination of the risk factors, by using the aflogit command in STATA (StataCorp, College Station, TX, USA) [30] on the logistic regression framework, as such an approach enables potential confounders to be taken into account.

\section{Results}

The response rate was $72 \%$, corresponding to a total of 4322 questionnaires that were duly completed by parents and returned to the investigators. The prevalence of habitual snoring was similar for male and females from ages 6-10 years (fig. 2). However, males had a significantly higher prevalence of habitual snoring at ages $11-12$ years $(\mathrm{p}<0.01)$ (fig. 2). Age-related declines in the frequency of habitual snoring occurred, especially at ages $\geqslant 9$ years (fig. 3). As such, the prevalence of habitual snoring in the 6- to 8-yearold children was significantly higher than at older ages (10-12 years; $\mathrm{p}<0.00001)$ (fig. 3).

In the bivariate analyses, the prevalence of habitual snoring was increased if allergic rhinitis, recurrent ear infections, asthma, tympanostomy tubes and/or previous adenotonsillectomy were also reported (tables 3 and 4). In addition, habitual snoring was more likely if a positive history of parental smoking or snoring was present (table 4).

Partition of habitual snoring rates according to neighbourhood air quality characteristics revealed that the frequency of habitual snoring was significantly higher among children residing in the neighbourhoods with poorest air quality when compared to the neighbourhoods with lowest degree of air pollution ( $24.5 \%$ versus $7.2 \%$, risk ratio 3.49 (95\% CI 2.67-6.69); $\mathrm{p}<0.0001$ ). The increasing risk effects of air pollution, although present for other respiratory symptoms such as asthma (risk ratio 1.86 (95\% CI 1.22-3.14); p $<0.01$ ), were not as pronounced as those identified for habitual snoring. The regional variance in the frequency of children fulfilling the criteria for habitual snoring was accounted for by the reported corresponding neighbourhood air quality indicators, even after controlling for all other risk factors delineated in table 3

TABLE 2 Pollutant standards index (PSI) for neighbourhoods during 2006-2007 in Tehran, Iran

\begin{tabular}{lccccc}
$\begin{array}{l}\text { PSI air status } \\
\text { 2007-2008 }\end{array}$ & & City region & \\
\cline { 2 - 5 } & North & West & Central & East & South \\
\cline { 2 - 6 } & 121 & 76 & 42 & 98 & 0 \\
Clean & 511 & 456 & 113 & 491 & 56 \\
Healthy & 68 & 168 & 525 & 111 & 537 \\
Nonhealthy & 0 & 0 & 16 & 0 & 78 \\
Extremely unhealthy & 0 & 0 & 4 & 0 & 29 \\
Dangerous & & & & & \\
\hline
\end{tabular}




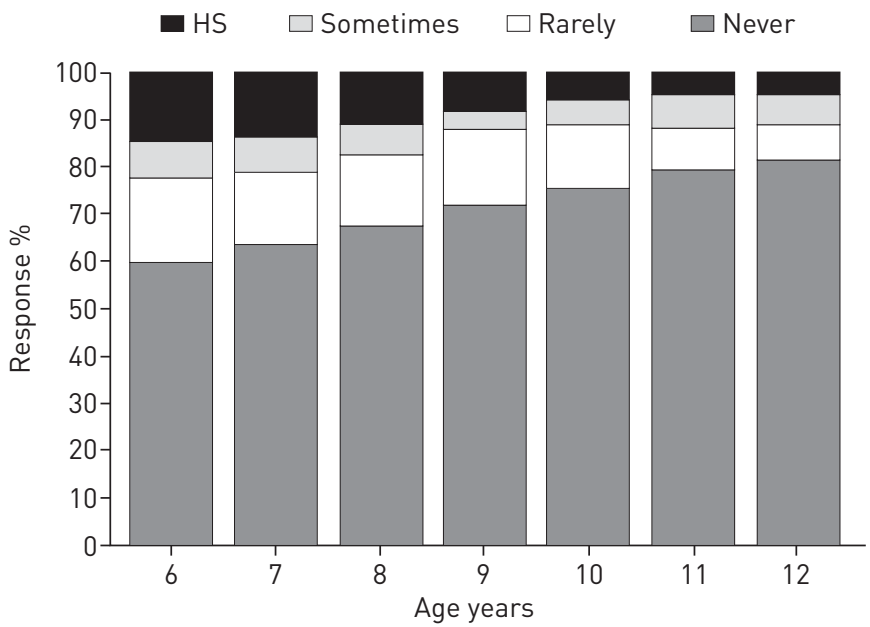

FIGURE 2 Percentage of responders to the "does your child snore?" question in the questionnaire administered to 4322 children according to age and based on "never", rarely", "sometimes" or "always or almost always" (i.e. $\geqslant 3$ nights per week or habitual snoring (HS)).

(risk ratio 1.94 (95\% CI 1.57-2.63); p<0.001) (table 4). Therefore, rather than include each of the air pollutants separately, we included either neighbourhood as the surrogate reporter of pollution levels or global PSI "non-healthy days", as both yielded comparable findings.

In the initial model adjusted only for age and sex, there was a robust effect of neighbourhood location or PSI "non-healthy day" group on the risk of snoring frequency in our cohort (risk ratio 3.46 (95\% CI 2.667.19); $\mathrm{p}<0.0001)$. Based on the bivariate significant associations between habitual snoring and clinical history elements (i.e. allergic rhinitis, recurrent ear infections, asthma, tympanostomy tubes and/or previous adenotonsillectomy), we included these elements in the second model, which again revealed that a robust component of the risk for habitual snoring was attributable to neighbourhood or PSI (risk ratio 2.34 (95\% CI 1.57-3.14); $\mathrm{p}<0.001$ ). Similar findings emerged when familial history components (i.e. parental snoring and smoking) were introduced into the model, with neighbourhood or PSI being associated with an increased risk for habitual snoring (risk ratio 3.18 (95\% CI 2.23-5.98); $<<0.0001$ ). We therefore proceeded to generate a third logistic stepwise regression model that incorporated both clinical and familial history elements. This model revealed that either neighbourhood location or PSI remained significantly associated with an increased risk for habitual snoring (risk ratio 1.87 (95\% CI 1.38-2.47); p <0.001). The regional differences of the risk ratio after adjusting for the all the potential confounders are shown in figure 4, using the northern region (lowest pollution) as reference. Because many of the covariates can be directly affected by pollution, we proceeded to perform a stepwise regression analysis that initially examined the association between habitual snoring and age, sex, parental cigarette smoking and all clinical history elements (risk ratio 2.43 (95\% CI 1.35-4.67); $\mathrm{p}<0.001)$. A second regression model was then calculated between PSI and parental smoking and clinical history characteristics (risk ratio 1.47 (95\% CI 1.03-2.23); p<0.01). The residuals from this model were used in the comprehensive model aiming to establish the adjusted association between PSI and habitual snoring, while adjusting for all other potential confounders and accounting for the interdependencies between air pollution and some of the key history elements. The findings from this model were remarkably similar to those described above as the third stepwise regression

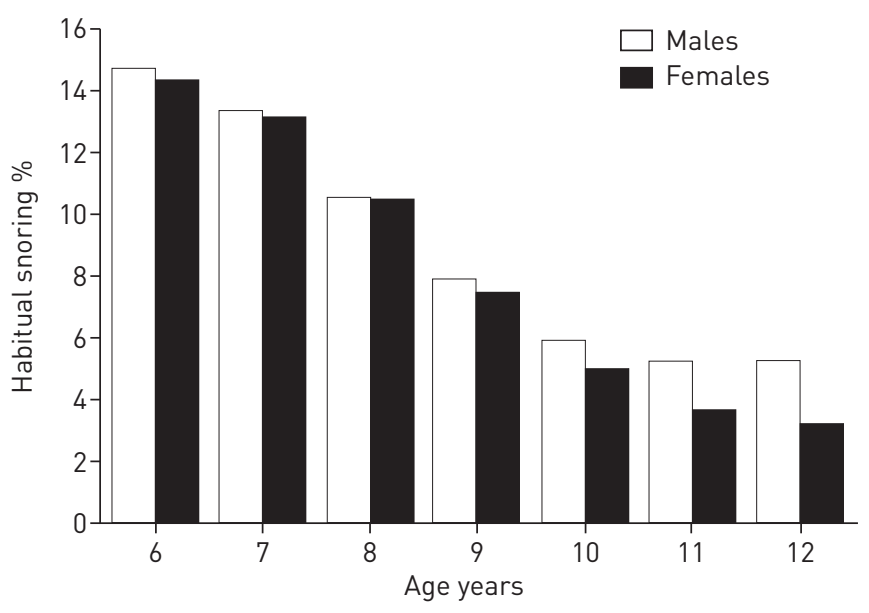

FIGURE 3 Percentage of children fulfilling the criteria for habitual snoring according to age and sex. 
TABLE 3 Overall prevalence of habitual snoring, allergy, asthma, recurrent otitis, tympanostomy tube placement and adenotonsillectomy in 4322 school-aged children living in Tehran, Iran, according to neighbourhood location

\begin{tabular}{|c|c|c|c|c|c|c|}
\hline Distribution per area & $4322(100)$ & 1011 (23.39) & $701(16.21)$ & $736(17.02)$ & $800(18.5)$ & 1074 (24.84) \\
\hline Allergy & $775(18.1)$ & 203 (20.38) & $165(23.6)$ & $141(19.31)$ & $100(12.62)$ & $166(15.58)$ \\
\hline Asthma & $191(4.4)$ & 37 (3.68) & $35(5.0)$ & 28 (3.83) & $55(6.85)$ & 36 (3.37) \\
\hline Recurrent ear infections & 185 (4.3) & $58(5.79)$ & $31(4.42)$ & $22(3.0)$ & $29(3.62)$ & $45(4.22)$ \\
\hline Tympanostomy tubes & $63(1.4)$ & $10(1.0)$ & $15(2.1)$ & $4(0.54)$ & $22(2.75)$ & $12(1.12)$ \\
\hline
\end{tabular}

Data are presented as $\mathrm{n}(\%)$. Bold indicates statistical significance.

model, i.e. that either neighbourhood location or PSI remained significantly associated with an increased risk for habitual snoring (risk ratio 1.83 (95\% CI 1.31-2.28); p <0.001). Exclusion of the clinical history elements from this model led, as would be predicted, to strengthening of the association between PSI and habitual snoring (risk ratio 2.83 (95\% CI 1.77-4.06); $\mathrm{p}<0.00001$ ). Using a statistical approach that allows multiple risk factors to be taken into account [30], a total of $37.8 \%$ of habitual snoring could be attributed to air pollutants (17\% to parental smoking, $20.8 \%$ to exposure to air pollution).

\section{Discussion}

This study shows that, in addition to other previously established individual or familial risk factors, environmental air pollution is an important contributor to the prevalence of habitual snoring in schoolaged children. Indeed, in this relatively homogeneous population of Iran, children residing within metropolitan neighbourhoods in which a substantial air pollution burden is present exhibited a much greater and independent risk for the presence of habitual snoring than children living in neighbourhoods where the environmental pollutants are not as high.

Tehran, the capital of Iran, is the one of the most populous and polluted cities in the Middle East. The city sprawls through a large surface area starting at the slopes of the Alborz mountains, and encompassing the large plains immediately at the foot of these mountains. The air quality in Tehran is largely defined by its geographical location, as the city is bound in the north by the high mountain range, which stops the flow of the humid Caspian wind, and in the south by the central desert plains. As a large city with significant differences in elevation among various districts, it exhibits marked differences in air quality. The regional characteristics and differences in air quality enabled us to carry out the present study, and to identify air pollution as yet another major risk factor for the presence of habitual snoring in school-aged children. However, notwithstanding our current findings, it is important to explore whether the same associations between air quality indicators and habitual snoring are confirmed in cities with less polluted air.

In past work, we have shown that an association between snoring and passive smoking is present in children, and that this association exhibits strong and dose-dependent effects with parental smoking (both parents smoking versus one smoking parent versus nonsmoking parents) on the frequency of snoring [4]. These dose-response relationships have since been confirmed by others and, considering that the strength of the association appears to be stronger in younger children who spend more time at home or when maternal smoking is involved as opposed to paternal smoking, there is plausibility for a causal relationship linking

TABLE 4 Unadjusted risk ratios for the presence of habitual snoring if previously identified risk factors were concurrently present among 4322 children living in Tehran, Iran

\begin{tabular}{lcc} 
& Relative risk (95\% Cl) & p-value \\
\hline Allergic rhinitis & $2.74(1.34-3.89)$ & $<0.01$ \\
Asthma & $3.46(1.55-4.73)$ & $<0.001$ \\
Recurrent ear infections & $2.37(1.12-3.44)$ & $<0.03$ \\
Status post tympanostomy tubes & $2.87(1.67-3.78)$ & $<0.001$ \\
Status post adenotonsillectomy & $4.78(2.72-7.66)$ & $<0.0001$ \\
Parental smoking & $2.25(1.44-3.66)$ & $<0.001$ \\
Parental habitual snoring & $2.43(1.39-3.87)$ & $<0.001$ \\
\hline
\end{tabular}




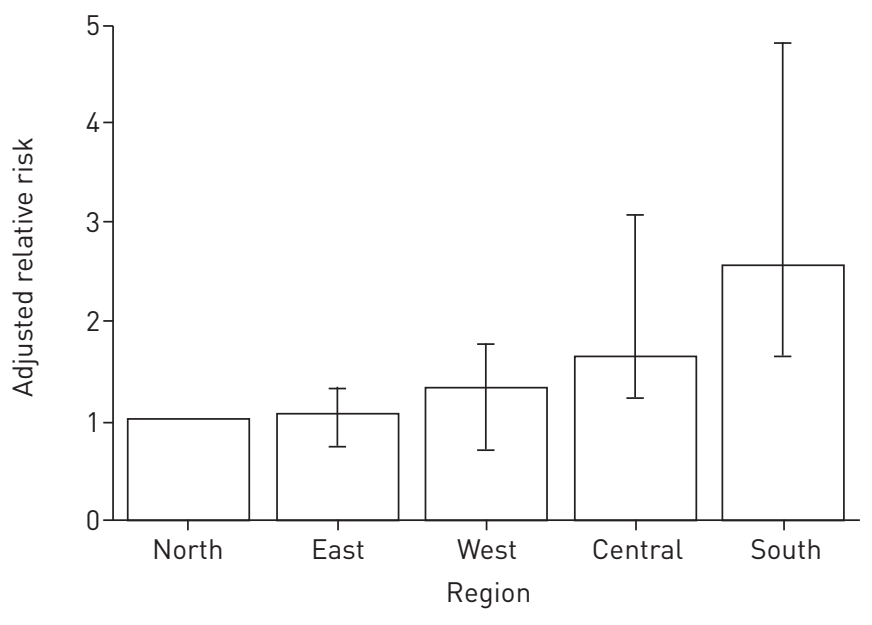

FIGURE 4 Regional relative risk for habitual snoring after adjusting for all potential confounders using the north region as the reference region. The increases in adjusted relative risk closely track the differences in air quality recorded for those regions.

exposure to cigarette smoking and habitual snoring [5, 18, 19, 31, 32]. These observations would further support the concept that other environmental pollutants may also contribute to the epidemiological characteristics of habitual snoring in children. Indeed, EKICI et al. [33] reported on the adverse effect of biomass pollution in rural areas as a major contributing factor to the presence of heightened prevalence of habitual snoring in rural environments. Recent work not only confirmed these assumptions, but further demonstrated that reduction in indoor biomass pollutants through targeted interventions, consisting of cooking stove replacements was associated with major improvements in the frequency of snoring [24]. Taken together, the existing evidence predicted that robust increases in the risk of habitual snoring would emerge in the current study among children living in the most polluted neighbourhoods, and this hypothesis was indeed confirmed.

Upper airway inflammation is consistently present among children with either habitual snoring or OSA [34, 35], and inflammatory processes within the upper airway are likely to exacerbate upper airway collapsibility, as well as promote the proliferation of adenotonsillar tissues. In this context, it has become apparent that short-term exposures to traffic-related air pollutants may increase airway inflammation and/or oxidative stress in urban children [36-38] and, therefore, such processes would be unlikely to be restricted to the lower airways and could, in fact, be even more prominent in the upper airways considering the relative concentrations of particles more likely to deposit in the upper segments of the airways [39, 40]. In this setting, the unique characteristics of the city of Tehran allowed us to design this study based on the presence of a relatively homogeneous population, and the differential distribution of environmental pollutant risk factors that may contribute to the presence of snoring in children. The increases in habitual snoring prevalence associated with higher environmental pollution exposures either per se, or after adjustment for other known risk factors, would support the contention that such exposures will elicit chronic inflammatory processes in the upper airway that either cause or at least promote upper airway lymphadenoid tissue proliferation, and the emergence of habitual snoring. Considering the adverse health-related morbidities associated with habitual snoring, it would be intriguing to determine whether specific pollution control measures in future studies would lead not only to reductions in habitual snoring prevalence, but also to amelioration in some of these habitual snoring-associated morbidities, e.g. academic performance, prevalence of attention deficit hyperactivity behaviours, nocturnal enuresis or hypertension [7, 8, 10-13, 41]. This possibility is all the more likely, when considering that at least one-third of the risk for habitual snoring is potentially attributable to avoidable risk factors [5].

Our study has replicated all of the previously identified risk factors for habitual snoring in other populations, including both clinical risk factors such as asthma, recurrent otitis and the need for tympanostomy tubes [42-44], as well as family-related risk factors, such as parental snoring [4, 5, 21]. The relative consistency and overall contribution of these factors across multiple ethnic and culturally diverse groups and environmental settings lends further credence to the existence of either causality or at least mediation relationships. However, we could not explore additional risk factors, such as obesity or history of respiratory syncytial virus infection using a questionnaire-based approach. Similarly, we cannot exclude with certainty that, despite efforts to validate the translated version of the questionnaire, certain terms may have different meanings in different countries and, therefore, can potentially lead to biased reporting.

Some methodological issues pertaining to the present study merit discussion. One of the major limitations of this study that is obviously shared by many of the other published community-based surveys is the lack of objective outcomes. Although we took precautions to translate and back-translate the questionnaire, it is 
important to note that the psychometric properties of the questionnaire were not specifically tested [45]. Moreover, although we have recently shown that the receiver operating characteristics of the questionnaire used herein are relatively favourable for screening OSA in community children, we cannot infer what proportion of the children who fulfilled the criteria for habitual snoring actually have OSA [29]. Furthermore, we did not have access to indoor pollution measurements or to specific school air quality measurements, such that the individual variations within each region could not be analysed with the desirable detail that would enable further confirmation of the global findings described herein. Furthermore, we opted to exclude potential questions about socioeconomic status under the assumption that such questions may markedly reduce participation in the survey. Notwithstanding, the regional differences in habitual snoring and their close tracking of the indicators of air quality provide a strong argument in support of a role for air pollutants in eliciting increased risk for habitual snoring in children.

In summary, in addition to previously identified risk factors, environmental air quality emerges as a significant and potentially modifiable contributor to the risk for developing habitual snoring during childhood, further emphasising the multiplicity of factors that operate as determinants of upper airway lymph adenoid proliferation.

\section{References}

1 Corbo GM, Fuciarelli F, Foresi A, et al. Snoring in children: association with respiratory symptoms and passive smoking. BMJ 1989; 299: 1491-1494.

2 Corbo GM, Forastiere F, Agabiti N, et al. Snoring in 9- to 15-year-old children: risk factors and clinical relevance. Pediatrics 2001; 108: 1149-1154.

Ferreira AM, Clemente V, Gozal D, et al. Snoring in Portuguese primary school children. Pediatrics 2000; 106: E64. O'Brien LM, Holbrook CR, Mervis CB, et al. Sleep and neurobehavioral characteristics of 5- to 7-year-old children with parentally reported symptoms of attention-deficit/hyperactivity disorder. Pediatrics 2003; 111: 554-563.

5 Kuehni CE, Strippoli MP, Chauliac ES, et al. Snoring in preschool children: prevalence, severity and risk factors. Eur Respir J 2008; 31: 326-333.

6 Chng SY, Goh DY, Wang XS, et al. Snoring and atopic disease: a strong association. Pediatr Pulmonol 2004; 38: 210-216.

7 O'Brien LM, Mervis CB, Holbrook CR, et al. Neurobehavioral implications of habitual snoring in children. Pediatrics 2004; 114: 44-49.

8 Gottlieb DJ, Chase C, Vezina RM, et al. Sleep-disordered breathing symptoms are associated with poorer cognitive function in 5-year-old children. J Pediatr 2004; 145: 458-464.

9 Gozal D. Sleep-disordered breathing and school performance in children. Pediatrics 1998; 102: 616-620.

10 Montgomery-Downs HE, Jones VF, Molfese VJ, et al. Snoring in preschoolers: associations with sleepiness, ethnicity, and learning. Clin Pediatr (Phila) 2003; 42: 719-726.

11 Gottlieb DJ, Vezina RM, Chase C, et al. Symptoms of sleep-disordered breathing in 5-year-old children are associated with sleepiness and problem behaviors. Pediatrics 2003; 112: 870-877.

12 Li AM, Au CT, Ho C, et al. Blood pressure is elevated in children with primary snoring. J Pediatr 2009; 155: 362-368.

13 Sans Capdevila O, Crabtree VM, Kheirandish-Gozal L, et al. Increased morning brain natriuretic peptide levels in children with nocturnal enuresis and sleep-disordered breathing: a community-based study. Pediatrics 2008; 121: e1208-e1214.

14 Spilsbury JC, Storfer-Isser A, Kirchner HL, et al. Neighborhood disadvantage as a risk factor for pediatric obstructive sleep apnea. J Pediatr 2006; 149: 342-347.

15 Rosen CL, Larkin EK, Kirchner HL, et al. Prevalence and risk factors for sleep-disordered breathing in 8- to 11year-old children: association with race and prematurity. J Pediatr 2003; 142: 383-389.

16 Ross KR, Storfer-Isser A, Hart MA, et al. Sleep-disordered breathing is associated with asthma severity in children. J Pediatr 2012; 160: 736-742.

17 Snow A, Dayyat E, Montgomery-Downs HE, et al. Pediatric obstructive sleep apnea: a potential late consequence of respiratory syncytial virus bronchiolitis. Pediatr Pulmonol 2009; 44: 1186-1191.

18 Li S, Jin X, Yan C, et al. Habitual snoring in school-aged children: environmental and biological predictors. Respir Res 2010; 11: 144.

19 Urschitz MS, Guenther A, Eitner S, et al. Risk factors and natural history of habitual snoring. Chest 2004; 126: 790-800.

20 Bixler EO, Vgontzas AN, Lin HM, et al. Sleep disordered breathing in children in a general population sample: prevalence and risk factors. Sleep 2009; 32: 731-736.

21 Li AM, Au CT, So HK, et al. Prevalence and risk factors of habitual snoring in primary school children. Chest 2010; 138: 519-527.

22 Zhang G, Spickett J, Rumchev K, et al. Snoring in primary schoolchildren and domestic environment: a Perth school based study. Respir Res 2004; 5: 19.

23 Zanobetti A, Redline S, Schwartz J, et al. Associations of PM10 with sleep and sleep-disordered breathing in adults from seven U.S. urban areas. Am J Respir Crit Care Med 2010; 182: 819-825.

24 Castañeda JL, Kheirandish-Gozal L, Gozal D, et al. Effect of reductions in biomass fuel exposure on symptoms of sleep apnea in children living in the Peruvian Andes: a preliminary field study. Pediatr Pulmonol 2013; 48: 996-999.

25 Schwartz J. Air pollution and children's health. Pediatrics 2004; 113: Suppl. 4, 1037-1043.

26 Krewski D, Jerrett M, Burnett RT, et al. Extended follow-up and spatial analysis of the American Cancer Society study linking particulate air pollution and mortality. Res Rep Health Eff Inst 2009; 140: 5-114.

27 Bateson TF, Schwartz J. Children's response to air pollutants. J Toxicol Environ Health A 2008; 71: 238-243. 
Montgomery-Downs HE, O’Brien LM, Holbrook CR, et al. Snoring and sleep-disordered breathing in young children: subjective and objective correlates. Sleep 2004; 27: 87-94.

29 Spruyt K, Gozal D. Screening of pediatric sleep-disordered breathing: a proposed unbiased discriminative set of questions using clinical severity scales. Chest 2012; 142: 1508-1515.

30 Brady AR. Adjusted population attributable fractions from logistic regressions. Stata Technical Bulletin 1998; 7: 137-143.

31 Montgomery-Downs HE, Gozal D. Snore-associated sleep fragmentation in infancy: mental development effects and contribution of secondhand cigarette smoke exposure. Pediatrics 2006; 117: e496-e502.

32 Kaditis AG, Finder J, Alexopoulos EI, et al. Sleep-disordered breathing in 3,680 Greek children. Pediatr Pulmonol 2004; 37: 499-509.

33 Ekici M, Ekici A, Keles H, et al. Risk factors and correlates of snoring and observed apnea. Sleep Med 2008; 9: 290-296.

34 Goldbart AD, Krishna J, Li RC, et al. Inflammatory mediators in exhaled breath condensate of children with obstructive sleep apnea syndrome. Chest 2006; 130: 143-148.

35 Kim J, Bhattacharjee R, Dayyat E, et al. Increased cellular proliferation and inflammatory cytokines in tonsils derived from children with obstructive sleep apnea. Pediatr Res 2009; 66: 423-428.

36 Graveland H, Van Roosbroeck SA, Rensen WM, et al. Air pollution and exhaled nitric oxide in Dutch schoolchildren. Occup Environ Med 2011; 68: 551-556.

37 Eckel SP, Berhane K, Salam MT, et al. Residential traffic-related pollution exposures and exhaled nitric oxide in the children's health study. Environ Health Perspect 2011; 119: 1472-1477.

38 Barraza-Villarreal A, Sunyer J, Hernandez-Cadena L, et al. Air pollution, airway inflammation, and lung function in a cohort study of Mexico City schoolchildren. Environ Health Perspect 2008; 116: 832-838.

39 Hoek G, Pattenden S, Willers S, et al. PM10, and children's respiratory symptoms and lung function in the PATY study. Eur Respir J 2012; 40: 538-547.

40 Liu MM, Wang D, Zhao Y, et al. Effects of outdoor and indoor air pollution on respiratory health of Chinese children from 50 kindergartens. J Epidemiol 2013; 23: 280-287.

41 Bonuck K, Freeman K, Chervin RD, et al. Sleep-disordered breathing in a population-based cohort: behavioral outcomes at 4 and 7 years. Pediatrics 2012; 129: e857-e865.

42 Lu LR, Peat JK, Sullivan CE. Snoring in preschool children: prevalence and association with nocturnal cough and asthma. Chest 2003; 124: 587-593.

43 Gozal D, Kheirandish-Gozal L, Capdevila OS, et al. Prevalence of recurrent otitis media in habitually snoring school-aged children. Sleep Med 2008; 9: 549-554.

44 Tauman R, Derowe A, Ophir O, et al. Increased risk of snoring and adenotonsillectomy in children referred for tympanostomy tube insertion. Sleep Med 2010; 11: 197-200.

45 Spruyt K, Gozal D. Development of pediatric sleep questionnaires as diagnostic or epidemiological tools: a brief review of dos and don'ts. Sleep Med Rev 2011; 15: 7-17. 